Article

\title{
Co-Firing of Sawdust and Liquid Petroleum Gas in the Application of a Modified Rocket Stove
}

\author{
Paisan Comsawang *, Suwat Nanetoe and Nitipong Soponpongpipat
}

Department of Mechanical Engineering, Faculty of Engineering and Industrial Technology, Silpakorn University, Nakhon Pathom 73000, Thailand; nanetoe.s@gmail.com (S.N.); Nitipongsopon@gmail.com (N.S.)

* Correspondence: comsawang_p@su.ac.th

Received: 5 December 2019; Accepted: 10 January 2020; Published: 15 January 2020

\begin{abstract}
The heating rate, firepower, and thermal efficiency of a modified rocket stove using sawdust and liquid petroleum gas (LPG) as co-firing fuel were investigated. Three modified rocket stoves with a height of $400 \mathrm{~mm}$ and outside diameters of 225,385 , and $550 \mathrm{~mm}$ were tested. It was found that there was an insignificant difference in heating rate and firepower when stoves were tested without co-firing with LPG. In this case, the stove heating rate was in the range of $1.49-1.55{ }^{\circ} \mathrm{C} / \mathrm{min}$. When LPG was used, the heating rate tended to linearly increase with the increase of LPG flow rate. The heating rate was in range of $2.42-2.80,2.63-3.27$, and 3.07-4.22 ${ }^{\circ} \mathrm{C} / \mathrm{min}$ when LPG consumption rates were $2.38 \times 10^{-5}, 3.33 \times 10^{-5}$, and $5.00 \times 10^{-5} \mathrm{~kg} / \mathrm{s}$, respectively. The slight increase of stove heating rate and firepower was seen when the stove diameter was increased from 225 to $385 \mathrm{~mm}$. The increase of stove diameter from 385 to $550 \mathrm{~mm}$ resulted in a huge increase of heating rate and firepower. Thermal efficiency of the sawdust stove without LPG decreased from $17.90 \%$ to $9.97 \%$ when the stove diameter was increased from 225 to $550 \mathrm{~mm}$. For co-firing of sawdust and LPG, the increase of LPG flow rate from $2.38 \times 10^{-5}$ to $5 \times 10^{-5} \mathrm{~kg} / \mathrm{s}$ caused the linear increase of thermal efficiency from $20.27 \%$ to $33.80 \%, 29.36 \%$ to $38.89 \%$, and $25.25 \%$ to $36.39 \%$ for the stove with diameters of 225,385 , and $550 \mathrm{~mm}$., respectively.
\end{abstract}

Keywords: sawdust; LPG stove; rocket stove; co-firing; pyrolysis

\section{Introduction}

Many peoples in regions of Southeast Asia used biomass stoves for the purposes of heating and cooking. A rocket stove is one of the widely used types due to its simple structure, flexibility of variation in solid biomass size, low fuel consumption and emissions compared to open fire or unimproved cookstove [1]. A rocket stove was first invented by Larry Winiarski [2]. Solid biomass fuel is combusted in an L-shaped combustion chamber. Primary air is naturally drafted into the combustion chamber through the feed tunnel of the stove. The secondary air is fed at the stove's top to cause the clean combustion. In the case of a rocket stove with long chimney, the sufficient forced draft resulting from the chimney effect causes continuous combustion and high thermal efficiency [3]. The drawback of this design is high construction cost and difficulty for installation. Usually, this stove design is used as rocket mass heaters for heating. A more simple design is a portable rocket stove. The draft in the portable rocket stove was created from a combination of combustion heat and the chimney effect $[4,5]$. This design is generally used for cooking. The rocket stove can be used with powdery and non-powdery biomass fuel [6]. For non-powdery biomass, direct combustion in presence of primary and secondary air was the main combustion mechanism. Continuous feed to the combustion chamber can be easily done for non-powdery biomass fuel. On the contrary, powdery biomass was used in the configuration of batch combustion. The biomass powder was compressed into briquette in the rocket stove. During compression, the L-shaped air flow channel was maintained inside the 
stove. Sawdust, partially mixing sawdust with leaves, dried plants, and wood chip are examples of biomass used in powdery form [7]. Sawdust is the most interesting feedstock. It was a large source of biomass waste which produced around 12-15 $\mathrm{kg}$ during processing of $100 \mathrm{~kg}$ of wood [8]. The rocket stove which uses sawdust as fuel was called a sawdust stove. Combustion mechanisms of sawdust stove consist of direct combustion of sawdust and combustion of volatiles produced from sawdust pyrolysis [6,9]. When the sawdust stove was ignited, heat produced from direct combustion of sawdust around the L-shaped air channel conducted through the sawdust block, resulting in pyrolysis of the block. The pyrolysis gas diffused through the block to the air channel and mixed with air. Due to a large amount of generated pyrolysis gas at the starting period, the air-fuel mixture was rich. This mixture flowed upward along the air channel and combusted at the stove's top. This combustion increased the air induction rate into the air channel, resulting in the increase of direct combustion rate. Consequently, the sawdust block temperature and pyrolysis gas production increased. The propagation rate of pyrolysis front also increased. However, conduction thermal resistance of the sawdust block decreased the propagation rate. Thus, pyrolysis gas production and combustion rate decreased in the next operation period. The decrease of pyrolysis gas production and combustion rate resulted in low temperature inside the stove. The flame disappeared and combustion inside the stove was like smoldering combustion $[10,11]$. To maintain the flame and high temperature inside the stove, it is necessary for portable sawdust stoves to continuously place a piece of wood into the combustion chamber. Without a piece of wood, the temperature of combustion chamber is low. Consequently, this stove generates much smoke. In the case of a small diameter stove, the high char yield was found, and the unburnt biomass was observed in a large diameter stove. However, after putting a piece of wood into the stove, violent flames and incomplete combustion were seen. A previous study on sawdust pyrolysis reported that pyrolysis gas yield increased, and char yield decreased when pyrolysis temperature increased [8]. It indicated that temperature of the combustion chamber was the important parameter for continuous operation of the stove. Thus, the proper additional heat is necessary for operating portable sawdust stoves efficiently. Instead of putting a piece of wood into the combustion chamber, liquid petroleum gas (LPG) is a better choice. LPG burning rate can be controlled easily, which means that additional heat will be put into the stove properly and continuously. In this method, the portable sawdust stove can operate efficiently over a long period. Study on co-firing of sawdust and LPG in this configuration may led to the decrease of LPG consumption in the cooking process of small enterprises in the food sector. However, there is no certainty of evidence on performance of this design. Moreover, LPG is a costly fuel. The overuse of LPG may be unnecessary.

This work modified a rocket stove in which sawdust was compressed and LPG as co-firing fuel was burnt. The investigation of thermal characteristics of this stove was conducted. The stove heating rate and firepower at various LPG flow rates and stove diameters were studied. The stove efficiency was also reported.

\section{Materials and Methods}

\subsection{Biomass Sample}

Sawdust was used in this experiment. It was gathered from Nakhon Pathom province $\left(13^{\circ} 49^{\prime} 1^{\prime \prime} \mathrm{N}\right.$ $100^{\circ} 3^{\prime} 57^{\prime \prime}$ E). The particle size of sawdust was smaller than $3 \mathrm{~cm}$. The moisture content of the sawdust was controlled in the range of $7 \% \pm 1 \%$ (w.b.). The higher heating value of pellet sample was measured using bomb calorimeter according to ASTM D5865-07. Lower heating value (LHV) was calculated and used for calculating stove efficiency. Details of sawdust properties and loading mass for each stove are shown in Table 1. 
Table 1. Sawdust properties and loading mass into each stove.

\begin{tabular}{|c|c|c|c|c|c|c|c|c|c|}
\hline & \multirow{2}{*}{$\begin{array}{c}\text { LHV } \\
\text { (MJ/kg) }\end{array}$} & \multicolumn{5}{|c|}{ Ultimate Analysis (Weight Percentages) } & \multicolumn{3}{|c|}{ Loading Mass into Stove (kg) } \\
\hline & & Ash & $\mathrm{C}$ & $\mathbf{H}$ & $\mathbf{O}$ & $\mathbf{N}$ & $\begin{array}{c}\text { Stove } 1 \\
(225 \mathrm{~mm})\end{array}$ & $\begin{array}{c}\text { Stove } 2 \\
(385 \mathrm{~mm})\end{array}$ & $\begin{array}{c}\text { Stove } 3 \\
(550 \mathrm{~mm})\end{array}$ \\
\hline Sawdust & 12.91 & 0.63 & 51.32 & 7.52 & 40.18 & 0.34 & 3.5 & 11 & 24 \\
\hline
\end{tabular}

\subsection{Experimental Setup}

The stove setup is shown in Figure 1. The modified rocket stove had a cylindrical shape with height of $400 \mathrm{~mm}$. It was made from an ASTM A36 steel plate. The circular plate with a hole of $63.5 \mathrm{~mm}$ at the center was welded at the bottom side of cylinder as a bottom plate. The LPG burner was installed at the hole of the bottom plate. A secondary air channel with a diameter of $63.5 \mathrm{~mm}$ was installed on a cylinder surface at a level of $20 \mathrm{~mm}$ above the bottom plate. The topside of the stove was covered with circular lid with a hole of $63.5 \mathrm{~mm}$. A steel pipe with a diameter of $63.5 \mathrm{~mm}$ was used as a mold to create an L-shaped air flow channel inside the stove. The combustion took place along the height of air flow channel. Thus, the air flow channel was called the combustion chamber when the stove was ignited. Ceramic fiber with a thickness of $50 \mathrm{~mm}$ was used as the insulator. Details of loading sawdust into the stove were as follows. Sawdust was filled and then compressed into the stove until the sawdust level reached $20 \mathrm{~mm}$ below the stove's top. Then, the ash-sand mixture was filled until it reached the topside of the stove to prevent combustion of sawdust at the top surface. Finally, the steel pipe mold was removed and then the stove was covered by the lid.

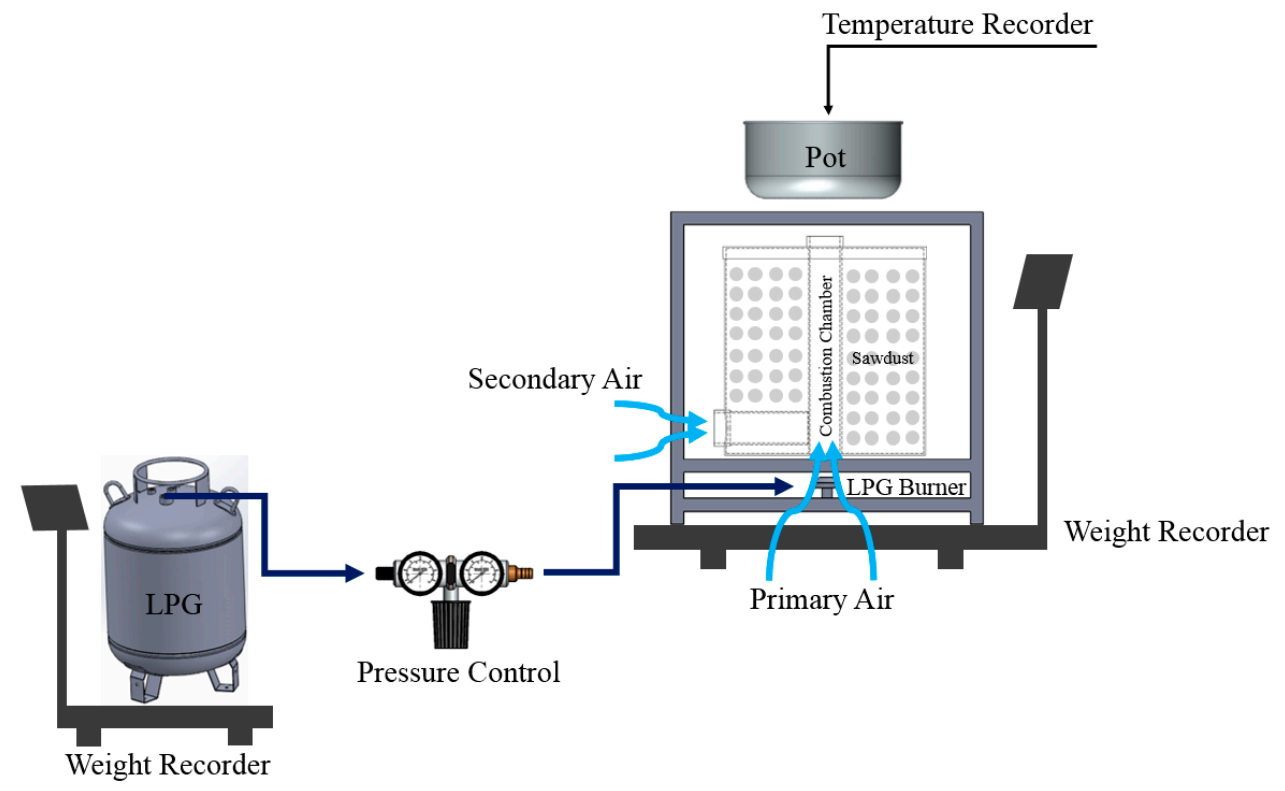

Figure 1. Stove setup.

To investigate the effect of stove diameter on the stove's thermal performance, the diameter of L-shaped air flow channel $\left(\mathrm{d}_{\mathrm{a}}\right)$ and the stove's height $(\mathrm{h})$ were kept constant while the stove's diameter $\left(D_{s}\right)$ was varied. According to the experiments of Mukunda et al. [6] and Bhaskar Dixit et al. [9], the ratio of stove diameter to air flow channel diameter $\left(D_{s} / d_{a}\right)$ was in range of $4.00-5.38$. To observe the stove performance in a wide range, this work assigned $D_{s} / d_{a}$ ratio around 4.0-8.0. Thus, the stove diameter was varied at 225,385 , and $550 \mathrm{~mm}$. The height of each stove was specified at $400 \mathrm{~mm}$. It was noted that the $\mathrm{h} / \mathrm{d}_{\mathrm{a}}$ ratio in this work was 6.30 . It was slightly higher than the value suggested by Mukunda et al. [6]. This value was acceptable because the unsteady and fluctuating flames occurred when the $\mathrm{h} / \mathrm{d}_{\mathrm{a}}$ ratio was very low. 
To study the effect of additional heat on stove performance, an LPG burner with a diameter of $50 \mathrm{~mm}$ was used as heat source. The LPG pressures were assigned at $0,7,14$, and 21 Pa to control LPG flow rates at $0,2.38 \times 10^{-5}, 3.33 \times 10^{-5}$, and $5.00 \times 10^{-5} \mathrm{~kg} / \mathrm{s}$, respectively. The sawdust consumption rate can be monitored by recording the weight loss of the sawdust in the stove every $3 \mathrm{~min}$.

The water boiling test was used to evaluate the stove heating rate and efficiency. Two aluminum pots with a diameter of $400 \mathrm{~mm}$ and height of $220 \mathrm{~mm}$ were used as water containers. Water of a $10 \mathrm{~kg} /$ pot was repeatedly heated from 28 to $80^{\circ} \mathrm{C}$. The mass of evaporated water during heating on the stove can be determined by the difference between the initial water mass $(10 \mathrm{~kg})$ and the water mass that remained in the pot when the temperature of $80^{\circ} \mathrm{C}$ was reached. When the heat transfer from the stove to pot reached the insignificant level, the mass and temperature of water in the pot were recorded. The weight loss of the stove was recorded as consumption mass of sawdust. The weight of the LPG container was also recorded to calculate LPG consumption.

The stove heating rate and firepower can be determined from the water temperature-time diagram obtained from water boiling test. The stove efficiency $(\eta)$ can be calculated by the following equation;

$$
\eta=\frac{\left[\mathrm{m}_{\mathrm{w}} \mathrm{c}_{\mathrm{w}}\left(\mathrm{T}_{\mathrm{b}}-\mathrm{T}_{0}\right)+\mathrm{m}_{\text {evap }} \mathrm{h}_{\mathrm{evap}}\right]}{\sum\left(\mathrm{m}_{\mathrm{p}} \mathrm{LHV} \mathrm{V}_{\mathrm{p}}\right)},
$$

where $\mathrm{m}_{\mathrm{w}}, \mathrm{m}_{\text {evap}}$, and $\mathrm{m}_{\mathrm{i}}$ represent initial mass of water, mass of evaporated water, and fuel consumption during the test. $\mathrm{T}_{\mathrm{b}}$ and $\mathrm{T}_{0}$ display water temperatures at the desired point $\left(80{ }^{\circ} \mathrm{C}\right)$ and initial point $\left(28^{\circ} \mathrm{C}\right)$, respectively. $\mathrm{c}_{\mathrm{W}}$ and $\mathrm{h}_{\text {evap }}$ represent specific heat capacity and enthalpy of evaporation. $\mathrm{LHV}_{\mathrm{p}}$ and $\mathrm{m}_{\mathrm{p}}$ indicate lower heating value and fuel consumption mass of each fuel type including sawdust and LPG.

\section{Results and Discussion}

\subsection{Stove Heating Rate and Firepower}

Figure 2 shows the relationship between the stove heating rate and the stove diameter. There was an insignificant difference in heating rate when stoves were tested without LPG. In this case, the stove heating rate was in range of $1.49-1.55{ }^{\circ} \mathrm{C} / \mathrm{min}$. When LPG was used to combust together with the compressed sawdust, the heating rate tended to nonlinearly increase with the increase of stove diameter. The heating rate was in the range of $2.42-2.80,2.63-3.27$, and $3.07-4.22^{\circ} \mathrm{C} / \mathrm{min}$ when the LPG consumption rate was $2.38 \times 10^{-5}, 3.33 \times 10^{-5}$, and $5.00 \times 10^{-5} \mathrm{~kg} / \mathrm{s}$, respectively. The slight increase of stove heating rate was seen when the stove diameter was increased from 225 to $385 \mathrm{~mm}$. The increase of stove diameter from 385 to $550 \mathrm{~mm}$ resulted in a huge increase of heating rate, especially in the case of the highest LPG consumption rate. When the data were plotted using the LPG consumption rate as the horizontal axis, the result can be seen in Figure 3. It was clearly seen that the stove heating rate linearly increased with the increase of LPG consumption rate. A vast change in the stove heating rate was found in case of the $550 \mathrm{~mm}$-stove. The firepower in the case of the stove without LPG was in range of 0.97-1.07 kW. These values were 2-3 times lower than that of the similar sawdust stove's diameter reported by earlier work $[6,7]$. Note that the firepower reported by previous work was calculated from the fuel consumption rate. This method was different from the present work. The firepowers of $1.68-2.15,1.84-2.47$, and $2.30-3.10 \mathrm{~kW}$ were found when the LPG flow rates were $2.38 \times 10^{-5}, 3.33$ $\times 10^{-5}$, and $5.00 \times 10^{-5} \mathrm{~kg} / \mathrm{s}$, respectively. The stove firepower tended to increase nonlinearly with the increase of stove diameter (Figure 4). When the LPG consumption rate was increased, the stove firepower linearly increased (Figure 5). 


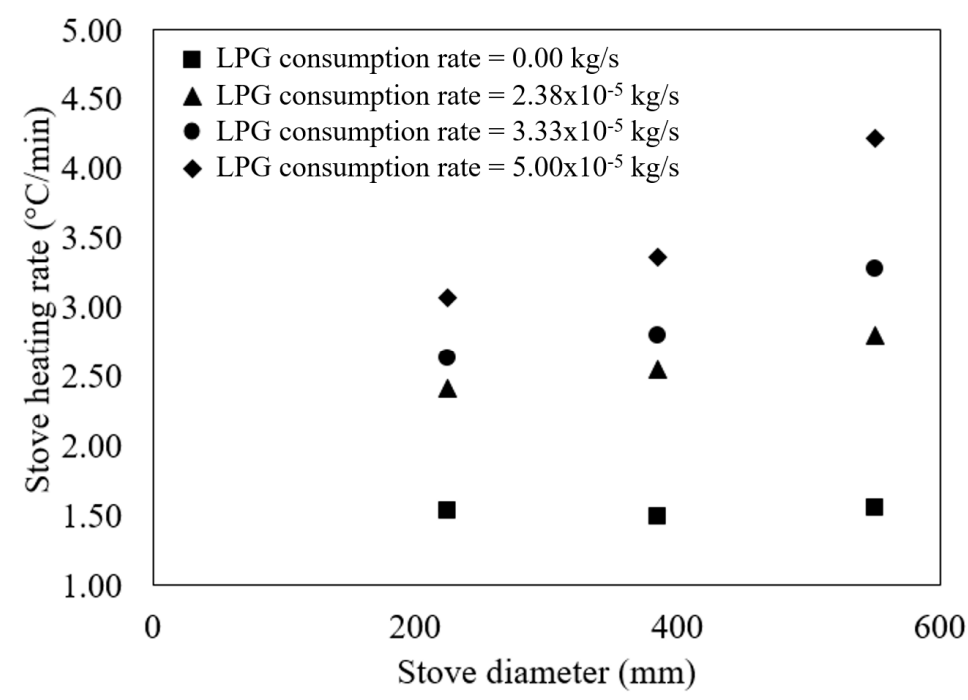

Figure 2. Relationship between stove heating rate and stove diameter.

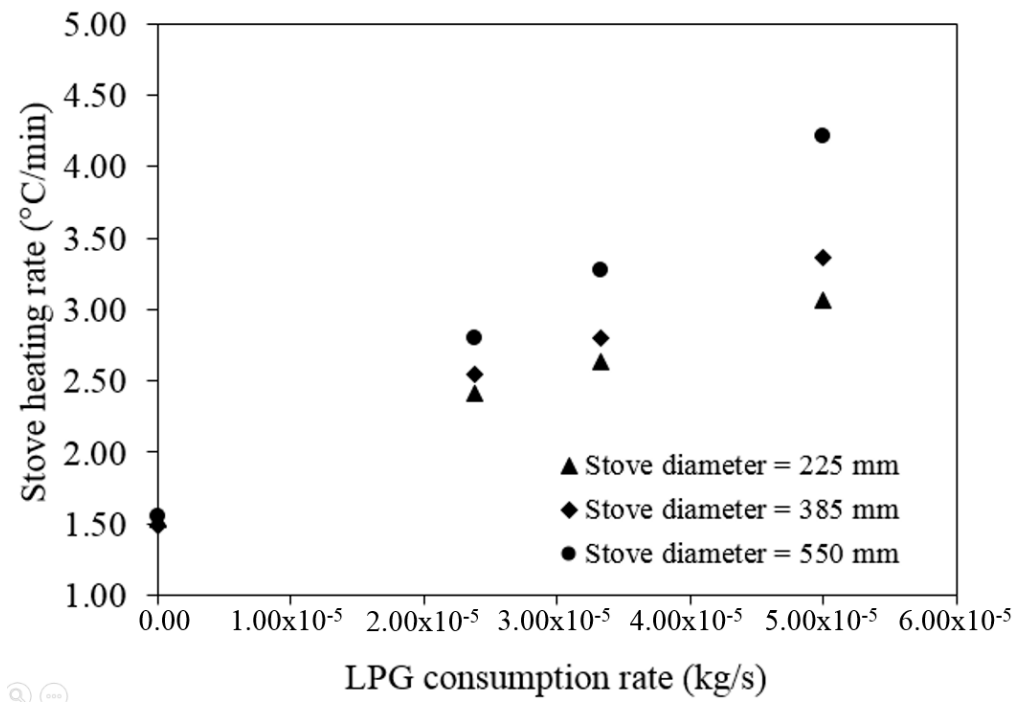

Figure 3. Relationship between stove heating rate and liquid petroleum gas (LPG) flow rate.

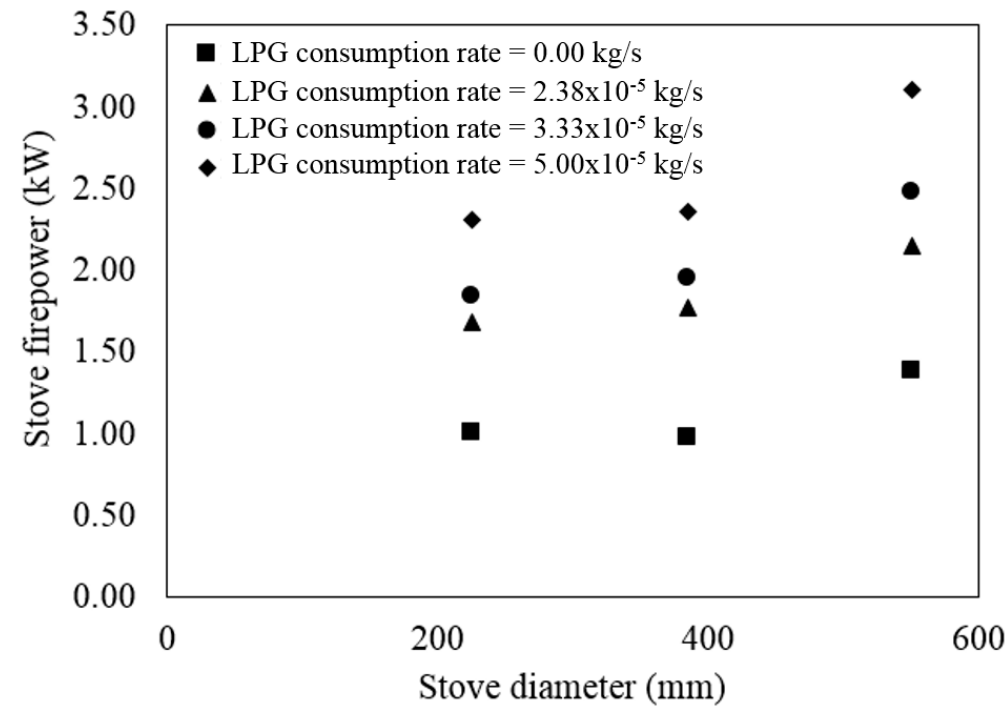

Figure 4. Relationship between firepower and stove diameter. 


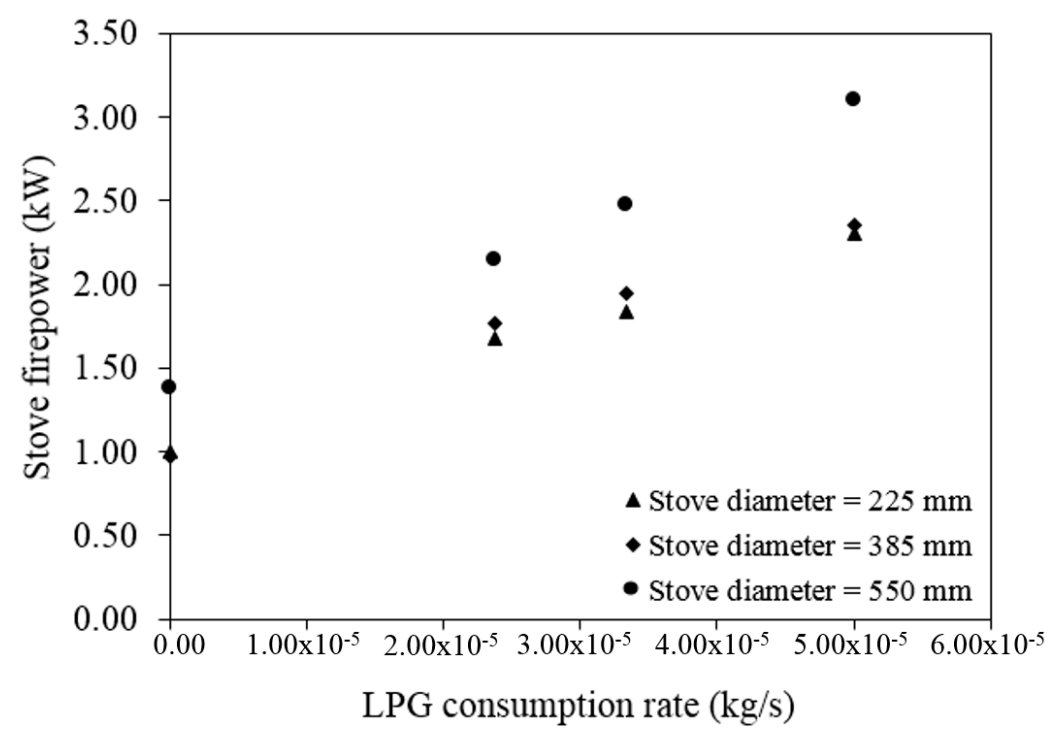

Figure 5. Relationship between firepower and LPG flow rate.

When the stove was tested without LPG, the increase of temperature inside the combustion chamber resulted from the direct combustion of the sawdust layer around the combustion chamber. Combustion heat conducted to an adjacent sawdust layer (Figure 6) contributing to the thermal degradation and volatile production in this layer. Due to the volatile pressure and the draft in combustion chamber, the volatile flowed from the decomposition layer to the combustion chamber. This flow direction obstructed permeability of air from the combustion chamber into the sawdust layer. Therefore, the direct combustion took place in the thin sawdust layer around the combustion chamber and a small amount of combustion heat was obtained. This caused the low temperature at the combustion chamber. A previous study reported the evidence of pyrolysis front propagation in a sawdust stove. The distribution of pyrolysis front in the form of a C-shape indicated that the radial depth of pyrolysis front decreased when the temperature of combustion chamber decreased [9]. Thus, combustion without additional heat from LPG led to the low sawdust decomposition and the volatile production rate. Consequently, heat obtained from the volatile combustion was low. In addition, the increase of stove diameter resulted in the increased of thermal resistance. It was reported that the pyrolysis in the sawdust stove occurred at the temperature range of 588-620 K $[6,9]$. The low combustion heat and high thermal resistance limited the thickness of the decomposition layer. Thus, similar heating rates of the stove at various diameters were seen in the case of the stove without LPG. When co-combustion between LPG and sawdust was conducted, the additional heat from LPG combustion increased the temperature of the combustion chamber and the rate of decomposition and volatile production, consequently, increased. The large amount of generated volatile gas resulted in a rich air/fuel mixture. It did not combust immediately but flowed along the height of the combustion chamber and combusted at the stove's top. This event was also reported by previous work [9]. Combustion heat of mixture at the stove's top and heat of LPG combustion increased the heating rate and firepower of the stove.

As discussed above, the additional heat from LPG combustion and the increase of stove diameter resulted in a wide range of stove heating rate and firepower. In other words, the heating rate and the firepower of sawdust-LPG co-firing in rocket stove can be controlled easily by controlling LPG flow rate. In fact, ability to control heating rate and firepower in a wide range is the strong point of an LPG cooking stove and the weak point of an ordinary sawdust stove. Due to this weak point, an ordinary sawdust stove is used in a long heating process and not suitable for a temperature-controlled cooking process. Co-firing of sawdust and LPG in a modified rocket stove overcomes this weak point and increased the flexibility of use in a long heating and temperature-controlled cooking process. 


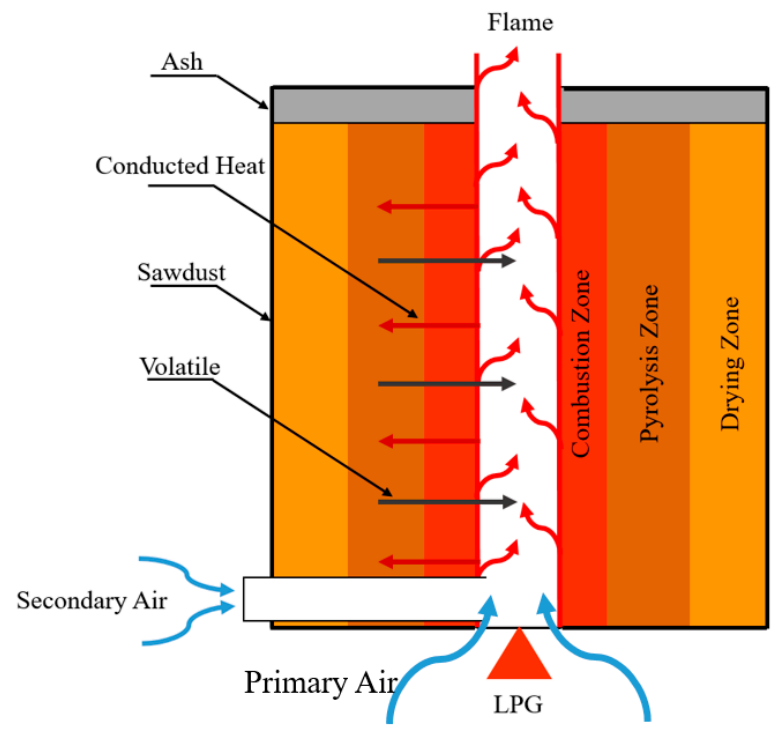

Figure 6. Sawdust layer in stove.

\subsection{Stove Efficiency}

The thermal efficiency of the stove without LPG decreased from $17.90 \%$ to $9.81 \%$ when the stove diameter was increased from 225 to $385 \mathrm{~mm}$. The slight change from $9.81 \%$ to $9.97 \%$ was found when the stove diameter was increased from 385 to $550 \mathrm{~mm}$. (Figure 7). Previous studies reported thermal efficiency of $24 \%$ for sawdust stove [7] and $27-32 \%$ of rocket stove fueling with Douglas Fir wood [5]. A single pot mud stove gave thermal efficiency around 14-18\% [12]. The sawdust stove without LPG had a poor thermal efficiency compared to the above stoves. The large amount of unburnt sawdust was found after finishing the test of stoves with diameters of 385 and $550 \mathrm{~mm}$. It signified that only the heat of sawdust combustion was insufficient to conduct the pyrolysis of an entire sawdust block in a large sawdust stove. Unburnt sawdust was a major cause of thermal efficiency drop. For co-firing of sawdust and LPG, the increase of LPG flow rate from $2.38 \times 10^{-5}$ to $5 \times 10^{-5} \mathrm{~kg} / \mathrm{s}$ caused the linear increase of thermal efficiency from $20.27 \%$ to $33.80 \%, 29.36 \%$ to $38.89 \%$, and $25.25 \%$ to $36.39 \%$ for the stove with diameters of 225, 385, and $550 \mathrm{~mm}$, respectively (Figure 8). For all values of LPG flow rate, the maximum thermal efficiency was found at the stove diameter of $385 \mathrm{~mm}$ (Figure 7). An earlier study proposed the empirical correlation for prediction of pyrolysis front propagation rate as $\dot{\mathrm{r}}=0.0094\left[\left(\mathrm{D}_{\mathrm{S}}-\mathrm{d}_{\mathrm{a}}\right) / 2\right]^{-0.13}[6]$. This correlation indicated that a stove with small diameter had a high pyrolysis front propagation rate. The volatile gas production rate was also high and incomplete combustion tended to occur easily. For the stove with a diameter of $225 \mathrm{~mm}$, it had a higher heat loss due to incomplete combustion compared to the others. Thus, the stove with diameter of $225 \mathrm{~mm}$ gave the lowest thermal efficiency for all values of LPG flow rate. However, the heat loss due to the unburnt sawdust played an important role for the stove with a large diameter as discussed above. This was the cause of the lower thermal efficiency of the stove with a diameter of $550 \mathrm{~mm}$ compared to that of one with the diameter of $385 \mathrm{~mm}$.

In addition, the maximum thermal efficiency of the improved LPG cooking stove was around $57.5 \%$ [13]. Although the maximum thermal efficiency of the 385-mm stove (38.89\%) was lower than that of the improved LPG cooking stove, it was acceptable when it was compared with the improved cooking stoves (their thermal efficiency was in the range of 25-37\%) [12]. In view of thermal efficiency, co-firing in the modified rocket stove was an interesting way. 


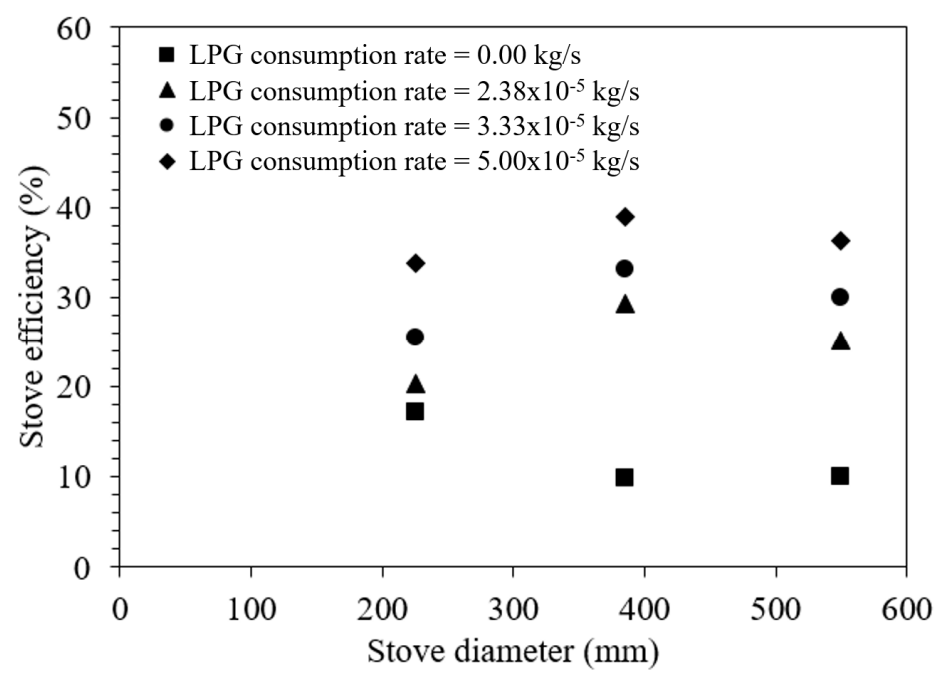

Figure 7. Relationship between stove efficiency and stove diameter.

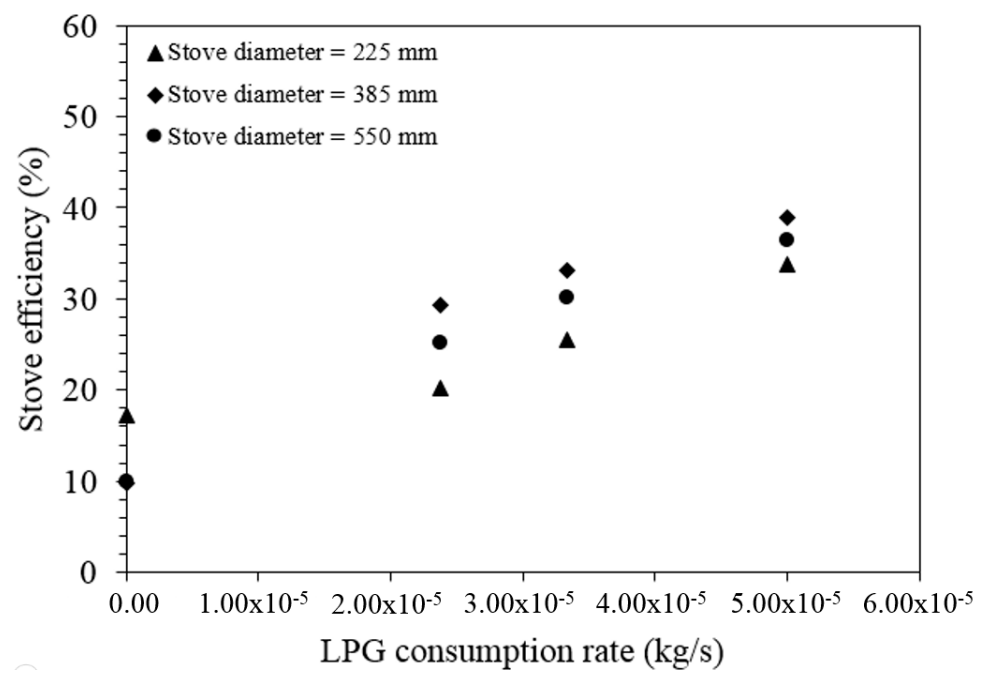

Figure 8. Relationship between stove efficiency and LPG flow rate.

\section{Conclusions}

This work proposed a new idea regarding co-firing between sawdust, which was powdery biomass, and LPG in a modified rocket stove. It was found from the investigation that the additional heat from LPG combustion in a modified rocket stove increased the stove heating rate, firepower, and thermal efficiency. In addition, the stove heating rate and firepower can be controlled by changing the LPG flow rate. With this co-firing configuration, the heating rate and firepower can be controlled in a wide range, which helped to increase flexibility of use in a long heating and temperature-controlled cooking process. Although there was a possibility to replace an LPG cooking stove with co-firing in modified rocket stove, it is still too early to introduce this co-firing configuration for use in real-life application. Further studies on emission control, safety operation, mathematical model, and economics analysis of this co-firing in a modified rocket stove are necessary.

Author Contributions: Conceptualization, P.C. and S.N.; Methodology, P.C., S.N. and N.S.; Software, P.C.; Validation, P.C., S.N. and N.S.; Formal Analysis, P.C.; Investigation, P.C., S.N. and N.S.; Resources, P.C., S.N. and N.S.; Data Curation, P.C., S.N. and N.S.; Writing-Original Draft Preparation, P.C., S.N. and N.S.; Writing-Review and Editing, P.C., S.N. and N.S.; Visualization, P.C. and S.N.; Supervision, S.N. and N.S.; Project Administration, P.C., S.N. and N.S.; Funding Acquisition, S.N. and N.S. All authors have read and agreed to the published version of the manuscript. 
Funding: This research was funded by Silpakorn University Research, Innovation and Creative Fund, grant number RD59M2-15.

Acknowledgments: The authors gratefully acknowledge Silpakorn University Research, Innovation and Creative Fund and Department of Mechanical Engineering, Faculty of Engineering and Industrial Technology, Silpakorn University, Sanam Chandra Palace Campus for all supports.

Conflicts of Interest: The authors declare no conflicts of interest.

\section{References}

1. Raman, P.; Murali, J.; Sakthivadivel, D.; Vigneswaran, V.S. Evaluation of domestic cookstove technologies implemented across the world to identify possible options for clean and efficient cooking solutions. J. Energy Chem. Eng. 2013, 1, 15-26.

2. $\quad$ Bryden, M.; Still, D.; Scott, P.; Hoffa, G.; Ogle, D.; Bailis, R. Design Principles for Wood Burning Cookstoves; US Environmental Protection Agency: Washington, DC, USA, 2005.

3. Schumack, M. A computational model for a rocket mass heater. Appl. Therm. Eng. 2016, 93, 763-778. [CrossRef]

4. Gandigude, A.; Nagarhalli, M. Review of rocket cook-stove geometrical aspects for its performance improvement. Mater. Today Proc. 2018, 5, 4743-4747. [CrossRef]

5. Pundle, A.; Sullivan, B.; Means, P.; Posner, J.D.; Kramlich, J.C. Predicting and analyzing the performance of biomass-burning natural draft rocket cookstoves using computational fluid dynamics. Biomass Bioenergy 2019, 131, 105402. [CrossRef]

6. Mukunda, H.S.; Dasappa, S.; Swati, B.; Shrinivasa, U. Studies on a stove for powdery biomass. Int. J. Energy Res. 1993, 17, 281-291. [CrossRef]

7. Grimsby, L.K.; Borgenvik, E.J.L. Fuelling sawdust stoves with jatropha fruit coats. Sustain. Energy Technol. Assess. 2013, 2, 12-18. [CrossRef]

8. Varma, A.K.; Thakur, L.S.; Shankar, R.; Mondal, P. Pyrolysis of wood sawdust: Effects of process parameters on products yield and characterization of products. Waste Manag. 2019, 89, 224-235. [CrossRef] [PubMed]

9. Bhaskar Dixit, C.S.; Paul, P.J.; Mukunda, H.S. Part I: Experimental studies on a pulverised fuel stove. Biomass Bioenergy 2006, 30, 673-683. [CrossRef]

10. Ohlemiller, T.J. Modeling of smouldering combustion propagation. Prog. Energy Combust. Sci. 1985, 11, 277-310. [CrossRef]

11. Ohlemiller, T.J. Smouldering combustion. In Society of Fire Protection Engineers' Hand Book of Fire Protection Engineering; National Fire Protection Association: Quincy, MA, USA, 1995.

12. Suresh, R.; Singh, V.K.; Malik, J.K.; Datta, A.; Pal, R.C. Evaluation of the performance of improved biomass cooking stoves with different solid biomass fuel types. Biomass Bioenergy 2016, 95, 27-34. [CrossRef]

13. Jugjai, S. Thermal efficiency improvement of an LPG gas cooker by a swirling central flame. Int. J. Energy Res. 2001, 25, 657-674. [CrossRef]

(C) 2020 by the authors. Licensee MDPI, Basel, Switzerland. This article is an open access article distributed under the terms and conditions of the Creative Commons Attribution (CC BY) license (http://creativecommons.org/licenses/by/4.0/). 